\title{
An experimental study of branching flow in open channels
}

\author{
Tarek Sayed
}

Department of Civil Engineering, Assiut University, 71515 Assiut, Egypt, e-mail: tareksayed1986@aun.edu.eg

\begin{abstract}
Branching channel flow describes any side water withdrawals from rivers or main channels. Branching channels have widespread application in many practical projects, such as irrigation and drainage network systems, water and waste-water treatment plants, and many water resources projects. Therefore, in this research, a comprehensive analysis of laboratory data has been carried out to discover the best angle of branching. The study also aims to introduce simple, practical equations to help engineers of water resources to fix the percentage of discharge diverted to the branch channel. The study was carried out in the Irrigation and hydraulics laboratory of the civil department, Faculty of Engineering, Assiut University. The laboratory channel consisted of two parts, the main channel, and a branch channel. The main channel was $8.0 \mathrm{~m}$ in length, $20 \mathrm{~cm}$ wide, and $20 \mathrm{~cm}$ in depth. The division corner to the branch channel was sharp edged and located $5.0 \mathrm{~m}$ downstream of the main channel inlet. The branch channel was $3.0 \mathrm{~m}$ long, $20 \mathrm{~cm}$ in depth and its width was changed three times (10, 15 , and $20 \mathrm{~cm}$ ) respectively. A total of 84 runs were carried out. Investigations of the flow into the branching channel show that the branching discharge depends on many interlinked parameters. It increases with a decrease of the main channel flow velocity and the Froude number upstream of the branch channel junction. It also increases with an increase in the $Y_{b} / Y_{u}$ ratio. In subcritical flow, water depth in the branch channel is always lower than the main channel water depth. The flow diversion to the branch channel leads to a decrease in water depth downstream of the main channel. In addition, the study showed that the highest discharge rate was obtained when the angle of branching was equal to $45^{\circ}$ and then an angle of $60^{\circ}$. While the lowest discharge rate was obtained at an angle of $90^{\circ}$. Furthermore, at $B_{r}=1.0$, using a branching angle equal to $45^{\circ}$ the discharge ratio $\left(Q_{r}\right)$ increases from about 4.42 to $19.01 \%$, more than that obtained with using the branching angle equal $90^{\circ}$, while the discharge ratio $\left(Q_{r}\right)$ increases from about 0.52 to $49.18 \%$ and 1.51 to $24.79 \%$, at $B_{r}=0.75$, and $B_{r}=0.5$ respectively.
\end{abstract}

Key words: diversion flow, main channel, branch channel, Froude number, branching angle

\section{Introduction}

In recent decades, extensive theoretical and experimental investigations of branching open channels have been performed to understand the characteristics of this branching flow. Branching channel flow still draws the attention of water resources engineering researchers as it commonly exists in many water engineering related projects, and due to the complexity of branching flow involving many interlinking factors it makes any generalization of the phenomenon difficult to achieve (Lama et al. 2002). Studying the flow in the diversion channel has a direct application in water supply plants, water treatment plants, as well as irrigation and drainage network system design (Ramamurthy et al. 1990). Constructing a branch channel to divert some of the water from the main flow affects the main channel flow and river bed mechanics, changing the bed form, especially in the junction region (Yonesi et al. 2008). These changes lead to many problems, such as changes in the main channel slope due to erosion and sedimentation in the main channel as well as on the branch channel.
Previous studies on branching channel flow have focused on the flow characteristics, such as branching flow discharge and regimes. For example, the earliest study conducted by Taylor (1944) investigated ways to appreciate a flow discharge in the branch channel. Based on experimental results, he proposed a graphical trial and error procedure for free flow branching flow discharge. Grace and Priest (1958) investigated branching flow with a different branch to the main bed width ratio with free overflow and classified the flow into two regimes, without standing waves for a relatively small Froude number flow and with local standing waves near the branch channel.

Research on branching channel flow later advanced with the exploration of theoretical equations. Ramamurthy and Satish (1988), Ramamurthy et al. (1990), and Hsu et al. (2002) deduced a theoretical model for branching flow into a right angle and short branch channel. Based on energy, momentum, and mass conservation principles and on the assumption that there is no energy loss along the main channel, Hager (1987), Kesserwani et al. (2010) and Ghostine et al. 
(2013) deduced their theoretical equations by treating the branching flow as a lateral flow over zero high side weirs. To the best of the author's knowledge, most of the branching channel flow studies have been done with a rigid boundary and a $90^{\circ}$ branching angle, while only a few researchers have studied different branching angles (e.g. Keshavarzi and Habibi 2005; Al Omari and Khaleel 2012; Khaleel et al. 2015) or with a movable bed condition (e.g. Kerssens and Van Urk 1986). Herrero et al. (2015), for example, studied a right angle diversion flow with a movable sand bed. He observed a scour hole constructed at the downstream edge of the branch channel entrance.

Another aspect that influences the branching channel system is the branching angle. Lama et al. (2002) noticed that the separation zone in the branch channel occurs in the downstream wall of a $30^{\circ}$ branching angle. On the other hand, it occurs in the upstream wall of a $90^{\circ}$ branching angle, e.g. Keshavarzi and Habibi 2005; Ramamurthy 2007; Herrero 2013 found from a laboratory study and by comparing separation zone sizes in different diversion angles $\left(45,56,67,79\right.$, and $\left.90^{\circ}\right)$ that the optimum angle of the diversion is $55^{\circ}$ according to the separation zone size in the intake channel. Based on the maximum branch channel discharge, the best angle for the diversion channel is $60^{\circ}$ from among 30, 60, and $90^{\circ}$ (Al Omari and Khaleel, 2012). An experimental study of the diversion channel from a $180^{\circ}$ bend main channel showed that a $45^{\circ}$ branching channel angle gave a maximum $\left(\mathrm{Q}_{\mathrm{r}}\right)$, for $\left(\mathrm{F}_{\mathrm{u}}\right)=0.47$ from among $45,60,75$, and $90^{\circ}$ (Masjedi and Taeedi 2011). Furthermore, a $60^{\circ}$ bend for the maximum diversion flow and a $45^{\circ}$ bend for other discharges gave a minimum amount of diverted sediment from among 45,60 , and $75^{\circ}$ (Pirestani et al. 2011). In addition, Dehghani et al. (2009) recommended using a $115^{\circ}$ branching channel from the bend flow because the upstream scour length is shorter than it is at $150^{\circ}$. Moreover, many researchers have studied the distribution of velocity components in the branching channel system experimentally (e.g. Ramamurthy et al. 2007; Bagheri and Heidarpour 2012) and numerically (e.g. Shamloo and Pirzadeh,2007a,b).

Lastly, branching channel flow is considered a very complex flow, as this flow depends on many factors, such as controlling gates at the end of the main and branch channel, velocity, Froude number and momentum in both the main and branch channels, and the geometry of the branching channel system. From this review, it is important to study the effect of the different branching channel geometries, such as branching angle on the flow in the main and branch channel.

\section{Material and methods}

Experiments were conducted in the irrigation and hydraulics laboratory of the Civil Engineering Department at Assiut University, Egypt. The laboratory channel consisted of two parts, the main channel, and a branch channel. A schematic layout of the experimental channel is shown in Figure 1. The main channel was 8.0 $\mathrm{m}$ long, $20 \mathrm{~cm}$ wide and $20 \mathrm{~cm}$ in depth. The division corner to the branch channel was sharp edged and lo-

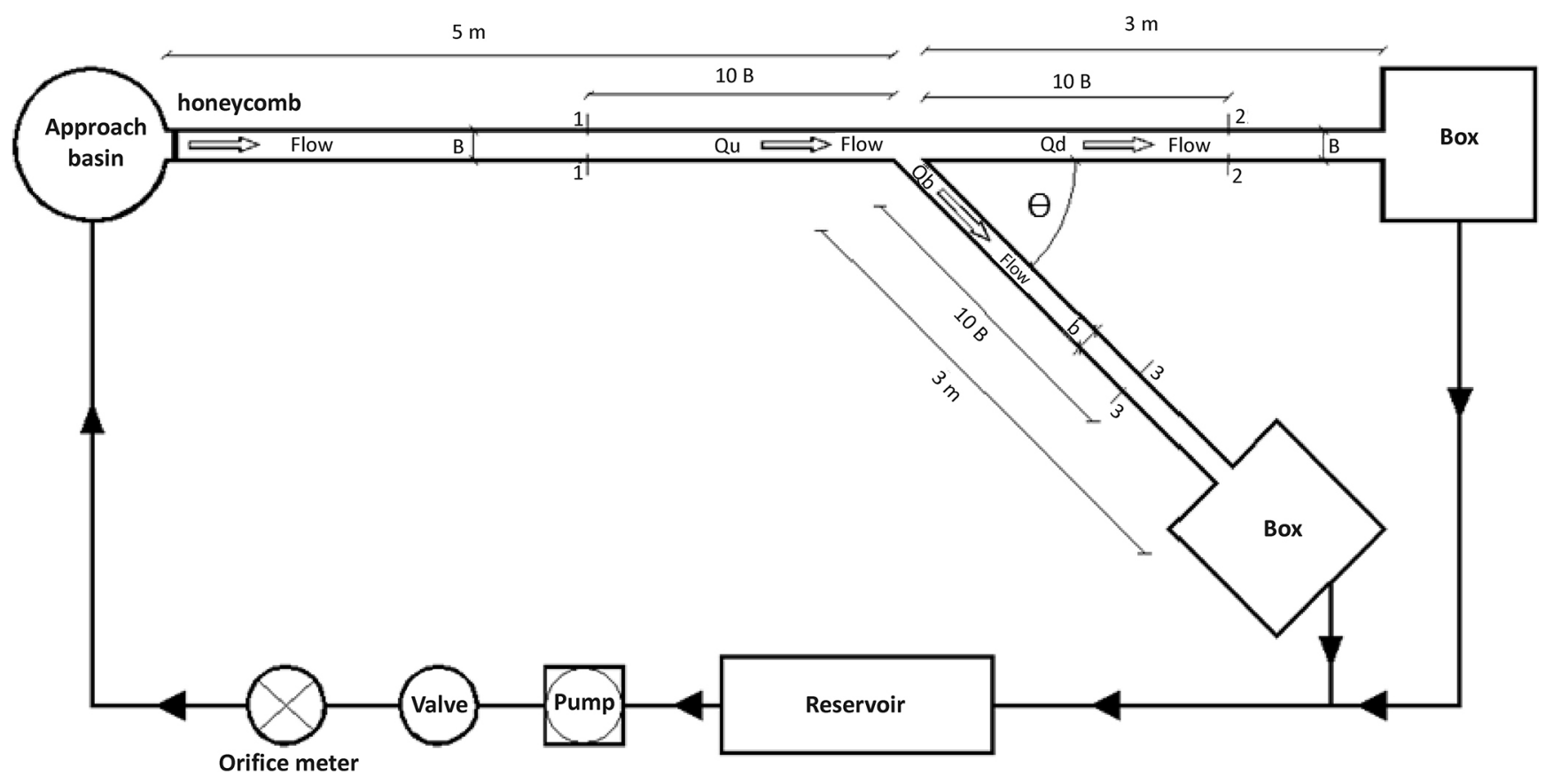

Fig. 1. Experimental set-up 
cated $5.0 \mathrm{~m}$ downstream of the main channel inlet. The branch channel was $3.0 \mathrm{~m}$ long, $20 \mathrm{~cm}$ in depth, and its width was changed three times, 10,15 , and $20 \mathrm{~cm}$, respectively. The water flow issued from an underground source. To assure the flow expansion as well as low turbulence, a honeycomb was set up at the entrance of the main channel. The discharges from the main and branch channels were measured by using the volumetric weight method. The water depths were measured at several cross-sections (Figure 1) with three vertical measurements in each cross-section. At the end of each channel it was necessary to ensure that the downstream flows were subcritical. All sections of the main and branch channels were taken at a distance equal to ten times the main channel width from the branch entrance.

The discharge in all observations varied between 1.28 and $7.47 \mathrm{dm}^{3} \mathrm{~s}^{-1}$. The downstream to upstream discharge ratios ranged from 0.42 to 0.76 . Froude number in the main channel upstream of the junction (measured $2 \mathrm{~m}$. upstream) varied from 0.34 to 0.74 . The branch channel Froude number well downstream of the junction (measured 2 metres away) ranged from 0.31 to 0.87 . For each run, the discharge in the branch channel, the discharge downstream of the main channel, the total discharge, the depths of flow at various sections were measured. The laboratory experiments were performed using three different values for the bed width ratio $\left(B_{r}\right)$ the branch channel to the main channel bed width $(b$ / $B)(B=0.5,0.75$, and 1.0$)$. For each bed width ratio, four different angles $\left(45,60,75\right.$ and $\left.90^{\circ}\right)$ were used to connect the branch channel to the main channel. For each branch angle, seven different discharges were passed through the main channel. All experiments were carried out with steady flow conditions. The flow downstream of the main and branch channel was free and subcritical. The total number of runs was 84 .

In each case, to perform the experiments, runs were started by connecting the branch channel to the main channel with any diversion angle. The storage feeding tank was filled with water. The intake valve of the feeding pipeline was opened slowly to give a definite value of discharge by adjusting both the intake valve and the water manometer reading. The downstream tailgate was removed to obtain free flow conditions. After a period of about 20 to 30 minutes the flow was steady. The discharges from the main and branch channels were measured by using the volumetric weight method. Afterwards, the diversion flow ratios were calculated. The water depths in the main and branch channels were measured at cross-sections, as shown in Figure 1.

Investigations of the flow into the branching channel show that the branching discharge depends on many interlinked parameters such as the main channel upstream discharge $\left(Q_{u}\right)$, the main channel downstream discharge $\left(Q_{d}\right)$, the branch channel discharge $\left(Q_{b)}\right.$, the water depths upstream and downstream in the main channel and in the branch channel $\left(Y_{u}, Y_{d}\right.$, and $Y_{b}$, respectively), the bed slope $(S)$, the branching angle $(\theta)$, the bed width ratio, the branch channel to main channel bed width $\left(B_{r}\right)$, the bed roughness, and the gravitational acceleration. The effect of the flow characteristics downstream of the main channel is negligible, due to the downstream tailgate being removed. Applying the dimensional analysis yields:

$$
Q_{r}=\varnothing\left(Y_{u} / Y_{d}, F_{u}, F_{b}, \theta, B_{r}\right)
$$

where:

$$
\begin{gathered}
Q_{r}=Q_{b} / Q_{u}<1.0, F_{u}=Q_{u} /\left[B Y_{u}\left(g Y_{u}\right)^{0.5}\right] \text {, and } F_{b}=Q_{b} \\
/\left[b Y_{b}\left(g Y_{b}\right)^{0.5}\right] .
\end{gathered}
$$

Equation 1 states that subcritical, free, branching channel flow over a horizontal bed can be characterized by $Y_{u} / Y_{d}, F_{u}, F_{b}, \theta$, and $B_{r}$.

\section{Results and discussion}

In the branching channel flow, some of the total discharge diverts towards the branch channel. The discharge ratio $\left(Q_{r}\right)$ is always used to describe a diversion flow in the branching channel. $\left(Q_{r}\right)$ is considered one of the most relevant parameters in the analysis of branching channel flow. This ratio depends on many factors, such as the Froude number upstream of the main channel and in the branch channel $\left(F_{u}\right.$, and $F_{b}$, respectively), the water depths upstream of the main channel and in the branch channel $\left(Y_{u}\right.$, and $Y_{b}$, respectively), the branching angle $(\theta)$, the bed width ratio, the branch channel to the main channel bed width $\left(B_{r}\right)$, and, if there is a side weir, the shape of the crest and weir height. Therefore, in this research, a comprehensive analysis of laboratory data has been carried out to reach the best angle of branching. Also, one of the main aims of this study was to introduce simple, practical equations to help engineers of water resources to fix the percentage of discharge diverted to the branch channel.

Experimental results were expressed in dimensionless forms and represented graphically to study the efficiency of using different angles of branching to connect the branch channel with the main channel on the discharge, velocity, depths of flow, and surface streamlines.

\section{Relationship between discharge ratio and bed width ratio}

In this study, a fixed bed width of the main channel of $20 \mathrm{~cm}$ was taken in all laboratory experiments, while in the branch channel the bed width was changed 

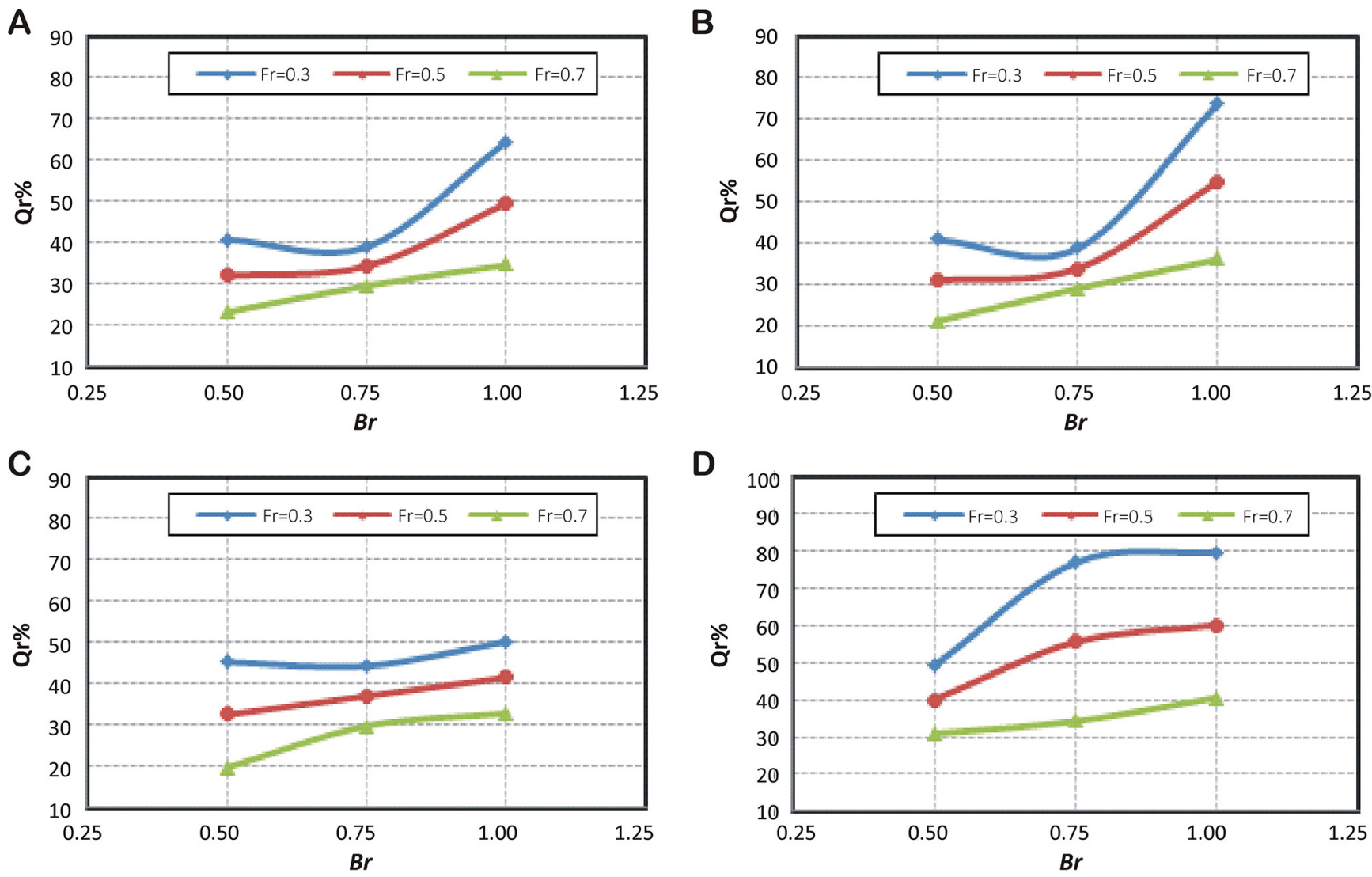

Fig. 2. Effect of the bed width ratio $\left(B_{r}\right)$ on division of flow at different branching angles $(\theta) . A: \theta=90^{\circ}, B: \theta=75^{\circ}, C: \theta=60^{\circ}$, and $D: \theta=45^{\circ}$

three times $(10,15$ and $20 \mathrm{~cm})$. To illustrate the effect of the change in the bed width ratio on the flow, the relationship between the discharge ratio $\left(Q_{r}\right)$ and the bed width ratio $\left(B_{r}\right)$ at different values of the Froude number upstream of the main channel $\left(F_{u}\right)$ for all understudy angles of branching, was plotted as shown in Figure 2. Generally, for all understudy angles of branching, there is a reverse relationship between $Q_{r}$ and $F_{u}$. Furthermore, $Q_{r}$ increases as the bed width ratio $\left(B_{r}\right)$ increases.

\section{Relationship between discharge ratio and Froude number}

To illustrate the effect of the velocity on the discharge of the branch channel $\left(Q_{b}\right)$, the relationship between the discharge ratio $\left(Q_{r}\right)$ and the Froude number upstream of the main channel and in the branch channel $\left(F_{u}\right.$, and $F_{b}$, respectively) for all understudy angles of branching, at different bed width ratios, was plotted as shown in
Figures 3 and 4 . It was observed that there is a strong linear relationship between the discharge ratio $\left(Q_{r}\right)$ and the Froude number in all cases. Moreover, there is a reverse relationship between $Q_{r}$ and $F_{u}$, which is consistent with the results of Krishnappa and Seetharamiah (1963), Hager (1987), and Bejestan et al. (2013), and between $Q_{r}$ and $F_{b}$. In addition, based on the maximum branch channel discharge, the best angle for the diversion channel is $45^{\circ}$ from among $45,60,75$, and $90^{\circ}$.

Based on the experimental data and using simple and multiple linear regression analyses, the best equation for predicting the discharge ratio for all understudy angles of branching, at $B_{r}=0.75$ for example, can be written in the following form:

$$
\begin{aligned}
& Q_{r} \%=a_{1}\left(F_{u}\right)+a_{2}, \\
& Q_{r} \%=a_{1}\left(F_{b}\right)+a_{2} .
\end{aligned}
$$

\begin{tabular}{|c|c|c|c|c|c|c|c|c|}
\hline \multirow{3}{*}{ Froude number } & \multicolumn{8}{|c|}{ Branching angle $[\Theta]$} \\
\hline & \multicolumn{2}{|c|}{$\theta=90^{\circ}$} & \multicolumn{2}{|c|}{$\theta=75^{\circ}$} & \multicolumn{2}{|c|}{$\theta=60^{\circ}$} & \multicolumn{2}{|c|}{$\theta=45^{\circ}$} \\
\hline & $a_{1}$ & $a_{2}$ & $a_{1}$ & $a_{2}$ & $a_{1}$ & $a_{2}$ & $a_{1}$ & $a_{2}$ \\
\hline$F_{u}$ & -23.46 & 46.11 & -24.12 & 46.11 & -36.27 & 55.23 & -106.5 & 108.83 \\
\hline$F_{b}$ & -32.52 & 48.31 & -38.46 & 49.80 & -75.04 & 70.14 & -156.11 & 166.12 \\
\hline
\end{tabular}

Table 1. Values of empirical coefficients $a_{1}$ and $a_{2}$ used in Eqns. 2 and 3 
The values of $\mathrm{R}^{2}$ ranged from 0.85 to 0.98 . The coefficients $\left(a_{1}\right.$ and $\left.a_{2}\right)$ are constants depending on the angle of branching; their appropriate values are given in Table 1 .

\section{Relationship between discharge ratio and water depth ratio}

From the laboratory investigation it was noted that in the main channel, the highest level of water occurs in
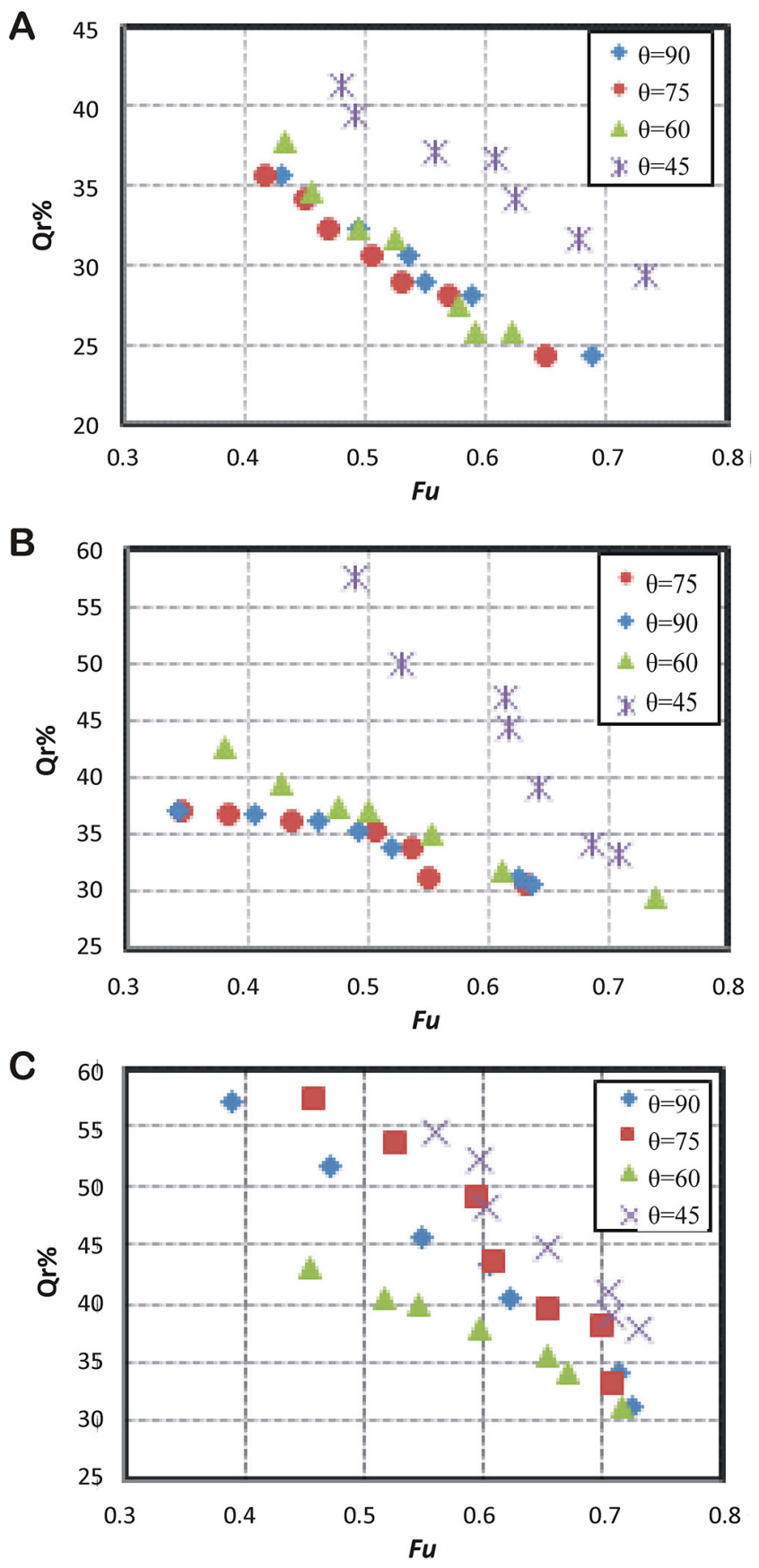

Fig. 3. Effect of the Froude number upstream of the main channel $\left(F_{u}\right)$ on division of flow at different bed width ratios $\left(B_{r}\right)$. A: $B_{r}=0.5$, B: $B_{r}=0.75$, and C: $B_{r}=1.0$ the first half of the junction region, and the lowest water level occurs just downstream of the junction region near the downstream edge of the branch channel. Also, in the branch channel, the water surface drops at the upstream corner at the entrance of the branch channel. The lowest water depth in the branch channel occurs in the contraction zone and starts to increase as the separation zone decreases, which is in agreement with the
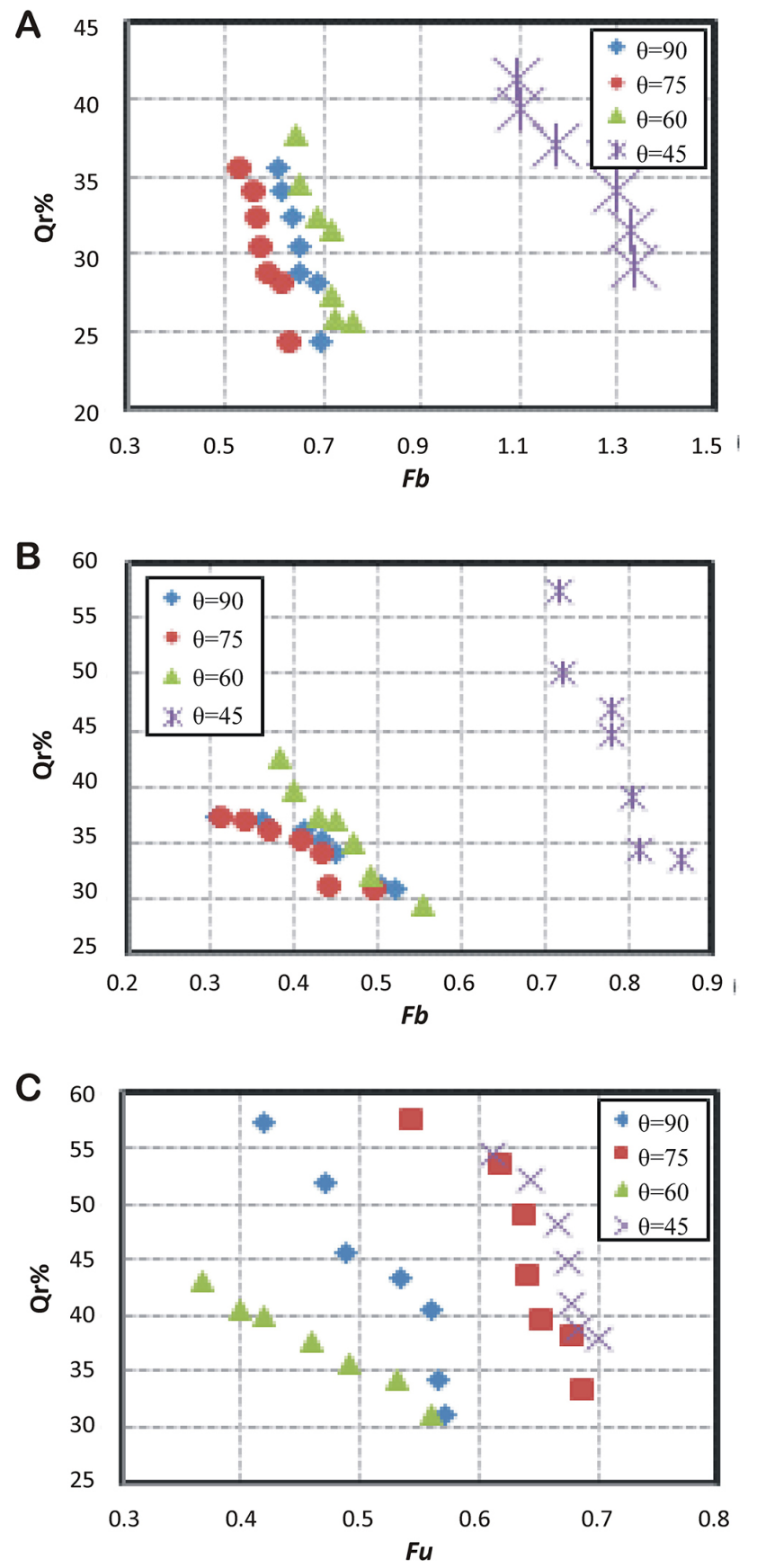

Fig. 4. Effect of the Froude number of the branch channel $\left(F_{b}\right)$ on division of flow at different bed width ratios $\left(B_{r}\right)$. A: $B_{r}=0.5, \mathrm{~B}: B_{r}=$ 0.75 , and $\mathrm{C}: \mathrm{B}_{\mathrm{r}}=1.0$ 
study results of Ramamurthy et al. (2007). Figure 5 was plotted to illustrate the relation between the discharge ratio $(Q)$ and the ratio between the water depths in the branch channel and upstream of the main channel (depth ratio). From this figure it is clear that there is a positive relationship between the $Q_{r}$ and $Y_{b} / Y_{u}$ ratio. Moreover, it was noticed that the main factors effecting the water depths in the branch channel system are discharge ratio and the Froude number. From this figure,
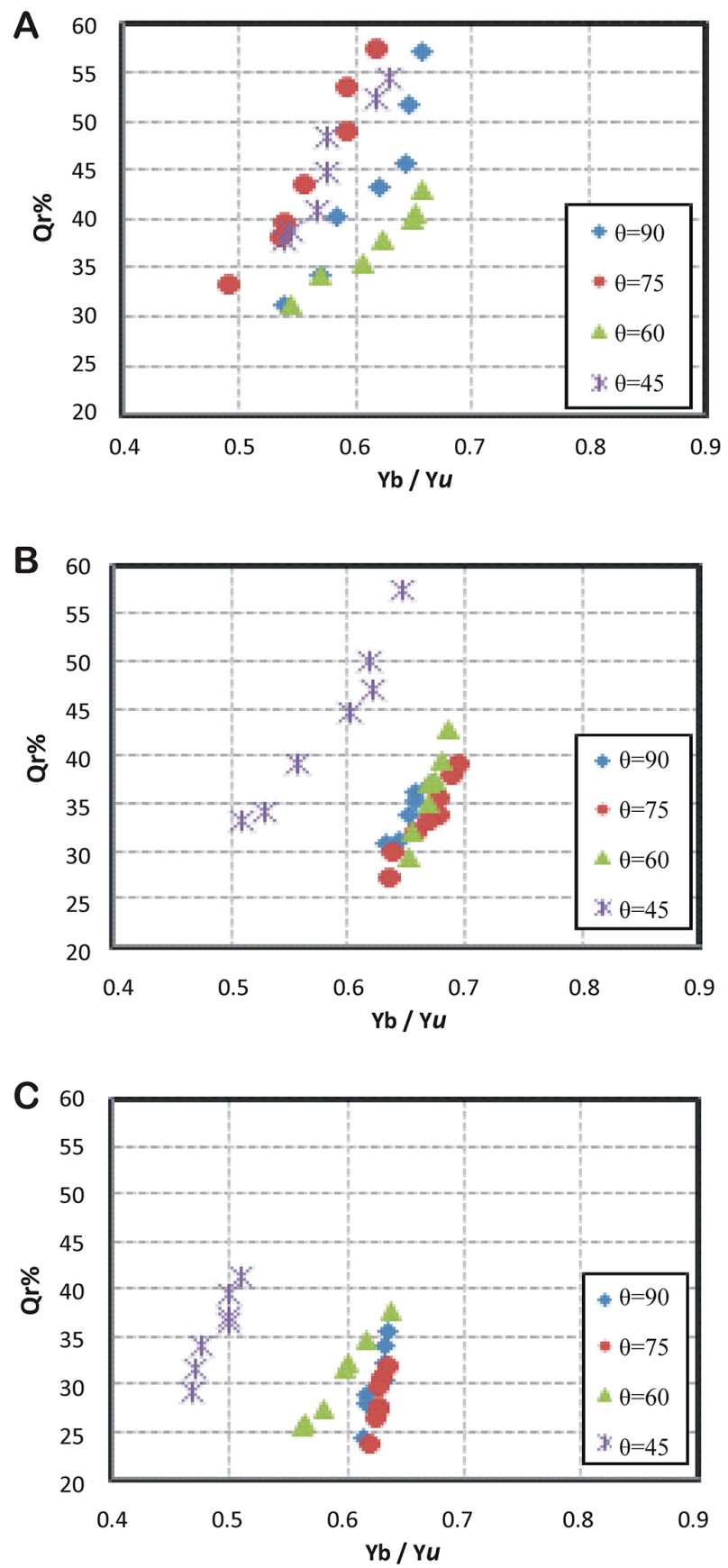

Fig. 5. Effect of the $Y_{b}$ to $Y_{u}$ ratio on division of flow at different bed width ratios $\left(B_{r}\right) . A: B_{r}=1.0, \mathrm{~B}: B_{r}=0.75$, and $\mathrm{C}: \mathrm{B}_{\mathrm{r}}=0.5$ it is also clear that for the same value of depth ratio ( $Y_{b}$ $\left(Y_{u}\right)$ the optimum angle of the diversion is $45^{\circ}$, which ensures that the largest amount of water is diverted to the branch channel.

Based on the experimental data and using simple and multiple linear regression analysis, the best equation for predicting the discharge ratio for all understudy angles of branching, at $B_{r}=1.0$ for example, can be written in the following form:
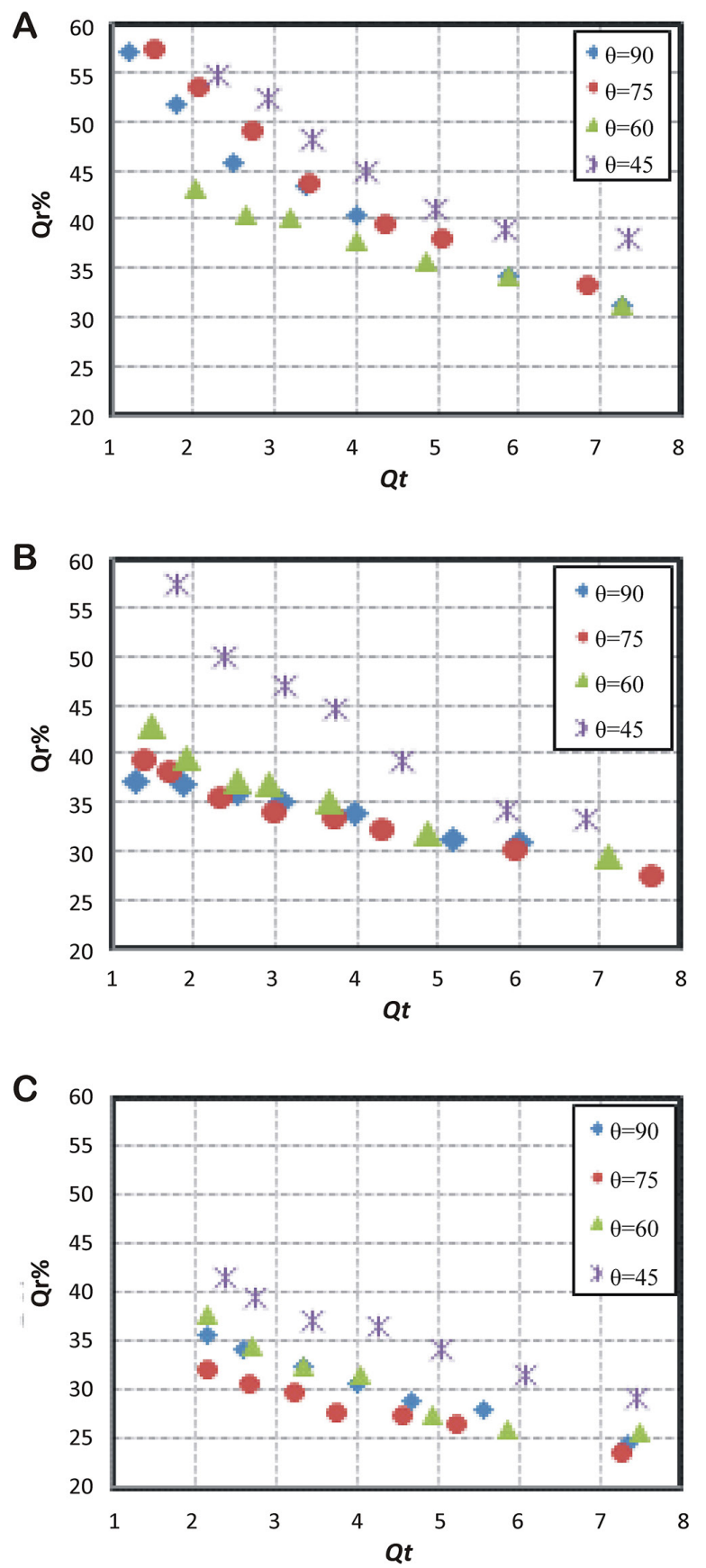

Fig. 6. Effect of the discharge ratio $\left(Q_{r}\right)$ ratio on division of flow at different bed width ratios $\left(B_{r}\right)$. A: $B_{r}=1.0, \mathrm{~B}: B_{r}=0.75$, and C: $\mathrm{B}_{\mathrm{r}}=0.5$ 
Table 2. Values of empirical coefficients $a_{1}, a_{2}$, and $a_{3}$ used in Equation 4

\begin{tabular}{|c|c|c|c|c|c|c|c|c|c|c|c|}
\hline \multicolumn{12}{|c|}{ Branching angle $[\Theta]$} \\
\hline \multicolumn{3}{|c|}{$\theta=90^{\circ}$} & \multicolumn{3}{|c|}{$\theta=75^{\circ}$} & \multicolumn{3}{|c|}{$\theta=60^{\circ}$} & \multicolumn{3}{|c|}{$\theta=45^{\circ}$} \\
\hline$a_{1}$ & $a_{2}$ & $a_{3}$ & $a_{1}$ & $a_{2}$ & $a_{3}$ & $a_{1}$ & $a_{2}$ & $a_{3}$ & $a_{1}$ & $a_{2}$ & $a_{3}$ \\
\hline 1125 & -1152 & 326.1 & 824 & -715 & 185.7 & 424 & -421 & 135 & -435.9 & 696 & 211 \\
\hline
\end{tabular}

$$
Q_{r} \%=a_{1}\left(Y_{b} / Y_{u}\right)^{2}+a_{2}\left(Y_{b} / Y_{u}\right)+a_{3} .
$$

The values of $\mathrm{R}^{2}$ ranged from 0.92 to 0.99 . The coefficients $\left(a_{1}, a_{2}\right.$ and $\left.a_{3}\right)$ are constant, depending on the angle of branching. Their values are given in Table 2.

\section{Relationship between discharge ratio and discharge in the upstream main channel}

Figure 6 shows the relation between the discharge ratio $\left(Q_{r}\right)$ and the total discharge upstream of the main channel $\left(Q_{t}=Q_{u}\right)$. From the figure, it can be seen that the highest discharge rate is obtained when the angle of branching is $45^{\circ}$ and then at an angle of $60^{\circ}$, while the lowest discharge rate is obtained at an angle of $90^{\circ}$. This is due to the way the branch channel and the main channel are connected, the extent of disturbance in the flow, and loss of energy in the branch region. When the used branching angle equals $45^{\circ}$ it allows a better flow from the main channel to the branch channel, thus reducing the disturbance in the flow and the loss of energy. When the angle of branching is $90^{\circ}$ there is a greater difficulty in diverting the water to the branch channel due to the phenomenon of continuity that makes the water continue in the first direction (towards downstream of the main channel) and decreases the amount of water that goes to the branch channel.

\section{Relation between discharge ratio and angle of branching}

Figure 7 shows the relationship between the discharge ratio $\left(Q_{r}\right)$ and the branching angle $(\theta)$ for differ-

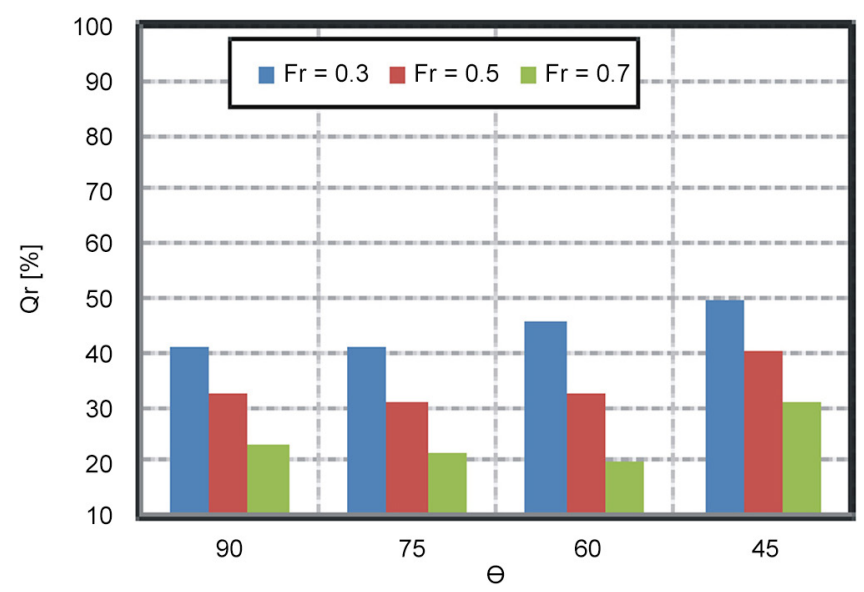

Fig. 7. Effect of the branching angle $(\Theta)$ on division of flow at different bed width ratios $\left(B_{r}\right)$. A: $B_{r}=1.0, B_{0}: B_{r}=0.75$, and C: $B_{r}=0.5$ ent values of the Froude number upstream of the main channel, at all understudy bed width ratios. These figures show the percentage of increase in the discharge ratio $\left(Q_{r}\right)$, using the branching angle 45,60 , and $75^{\circ}$ to be more than that obtained using the branching angle $90^{\circ}$.

From the figure it is clear that, at $B_{r}=1.0$, using a branching angle equal $\theta=45^{\circ}$ increases the discharge ratio $\left(Q_{r}\right)$ with about 4.42 to $19.01 \%$ more than that obtained when using a branching angle equal $90^{\circ}$, while the discharge ratio $Q_{r}$ increases from about 0.52 to $49.18 \%$ and from 1.5 to $24.79 \%$, at $B_{r}=0.75$, and $B_{r}=$ 0.5 respectively.

For predicting an equation to determine the discharge ratio $\left(Q_{r}\right)$ which describes the diversion flow in the branching channel for the optimum angle of branching $\left(\theta=45^{\circ}\right)$, as a function of the Froude number upstream of the main channel and in the branch channel, and the ratio between the water depths in the branch channel and upstream of the main channel, simple and multiple linear regression analyses were used. The equation derived from the statistical program SPSS by using two-thirds of the values of the measured variables can be written in the following form:

$$
\begin{aligned}
& Q_{r} \%=-34.505\left(F_{u}\right)-2.791\left(F_{b}\right)+99.478\left(Y_{b} / Y_{u}\right)+ \\
& 10.696 \text {. }
\end{aligned}
$$

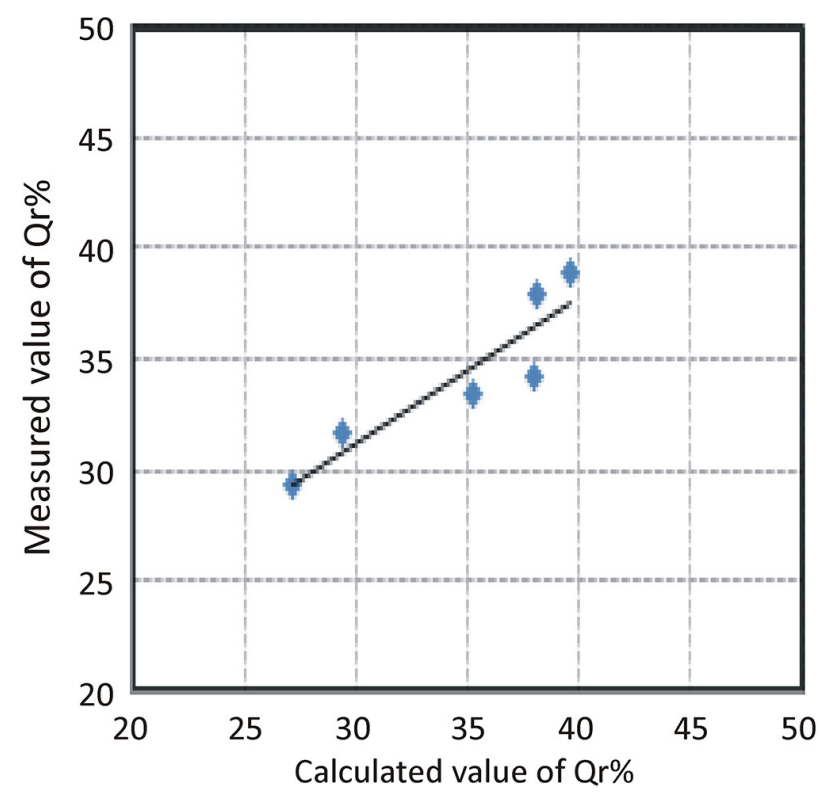

Fig. 8. Comparison between measured and calculated values of discharge ratios $\left(Q_{r}\right)$ using Equation 4 at the branching angle $\theta=45^{\circ}$ 
The value of $\mathrm{R}^{2}$ equals 0.946 . The remaining third of the values of the variables were used for verifying Equation 5 . Figure 8 shows a comparison between the measured discharge ratio $\left(Q_{r}\right)$ and the calculated one using the developed Equation 5. It can be seen that the predicted data have a good agreement with the measured data, since the error rate did not exceed $\pm 7 \%$.

\section{Conclusions}

Through the present study and its experimental results the following main conclusions can be drawn:

1. Regarding flow characteristics, the branching discharge decreases as velocity, Froude number and momentum in the upstream main channel flow increases. Moreover, it increases by increasing the upstream main channel water depth and branch channel bed width.

2. In subcritical flow, the water depth in the main channel decreases in the downstream diversion area. On the other hand, it decreases in its depth in the branch channel.

3. In subcritical flow, water depth in the branch channel is always lower than the main channel water depth.

4. The flow diversion to the branch channel leads to a decrease of water depth downstream of the main channel.

5. The highest discharge rate is obtained when the angle of branching $(\theta)$ is $45^{\circ}$ and then at an angle of $60^{\circ}$, while the lowest discharge rate is obtained at an angle of $90^{\circ}$.

6. At $\mathrm{Br}=1.0$, using a branching angle equal to $45^{\circ}$ increases the discharge ratio $\left(Q_{r}\right)$ from about 4.42 to $19.01 \%$ more than that obtained when using a branching angle equal to $90^{\circ}$, while the discharge ratio $\left(Q_{r}\right)$ increases from about 1.50 to $49.18 \%$ and 0.52 to $24.79 \%$, at $\mathrm{Br}=0.75$, and $\mathrm{Br}=0.5$ respectively.

\section{Notation}

The following symbols are used in this paper:

- $B$ - main channel bed width;

- $B_{r}$ - bed width ratio, branch channel to main channel bed width;

- $F_{b}$ - Froude number of the branch channel;

- $F_{d}$ - Froude number downstream of the main channel;

- $F_{u}$ - Froude number upstream of the main channel;

- $Q_{b}^{u}$ - branch channel discharge;

- $Q_{d}$ - main channel downstream discharge;

- $Q_{t}$ - total discharge, and its equal $\mathrm{Qu}$;

- $Q_{u}$ - main channel upstream discharge;

- $Q r$ - discharge ratio;

- $S$-bed slope of the main channel;
- $S_{b}$ - bed slope of the branch channel;

- $Y_{b}$ - water depth in the branch channel;

- $Y_{d}$ - water depth downstream of the main channel;

- $Y_{u}$-water depth upstream of the main channel;

- $a_{1}$ - coefficient depending on the angle of branching;

- $a_{2}-$ coefficient depending on the angle of branching;

- $a_{3}$ - coefficient depending on the angle of branching;

- $b$ - branch channel bed width;

- $g$ - gravitational acceleration;

- $\theta$ - branching angle.

\section{References}

Al Omari N.K., Khaleel M.S., 2012, Laboratory study of the effect of the branching angle and the branching channel slope on flow, Al-Rafadain Eng. J. (AREJ) 20(5): 33-41.

Bagheri S., Heidarpour M., 2012, Characteristics of flow over rectangular sharp-crested side weirs, J. Irrig. Drain. Eng. 138(6): 541-547.

Bejestan S.M., Moghaddam M.K, Seyedian M., 2013, Best flow condition for lateral intakes of irrigation canals, Proc. of the 14th TSAE Nat. Conf. and the 6th TSAE Int. Conf., 1-4 April 2013, Hua Hin (Thailand): 170-174.

Dehghani A., Ghodsian M., Suzuki K., Alaghmand S., 2009, Local scour around lateral intakes in 180 degree curved channel, [in:], Zang C., Tang H. (eds) Advances in water resources and hydraulic engineering, Springer, BerlinHeidelberg: 821-825.

Ghostine R., Vazquez J., Terfous A., Rivière N., Ghenaim A., Mosé R., 2013, A comparative study of 1D and 2D approaches for simulating flows at right angled dividing junctions, Appl. Math. Comput. 219(10): 5070-5082.

Grace J.L., Priest M.S., 1958, Division of flow in open channel junctions, Bulletin No 31, Engineering Experiment Station, Alabama Polytechnic Institute, Auburn, 421 pp.

Hager W., 1987, Lateral outflow over side weirs, J. Hydraul. Eng. 113(4): 491-504.

Herrero A., 2013, Experimental and theoretical analysis of flow and sediment transport in 90-degree fluvial diversions [ $\mathrm{PhD}$ thesis], Universitat Politécnica de Catalunya, Barcelona, $176 \mathrm{pp}$.

Herrero A., Bateman A., Medina V., 2015, Water flow and sediment transport in a $90^{\circ}$ channel diversion: an experimental study, J. Hydraul. Res. 53(2): 253-263.

Hsu C., Tang C., Lee W., Shieh M., 2002, Subcritical 90 equal-width open-channel dividing flow, J. Hydraul. Eng. 128(7): 716-720.

Kerssens P., van Urk A., 1986, Experimental studies on sedimentation due to water withdrawal, J. Hydraul. Eng 112(7): 641-656.

Keshavarzi A., Habibi L., 2005, Optimizing water intake angle by flow separation analysis, Irrig. Drain. 54(5): 543-552. 
Kesserwani G., Vazquez J., Rivière N., Liang Q., Travin G., Mosé R., 2010, New approach for predicting flow bifurcation at right-angled open-channel junction, J. Hydraul. Eng 136(9): 662-668.

Khaleel M.S, Taha K.Y., Alomari N.K., 2015, Effect of main channel roughness on the branching flow, Al-Rafadain Eng. J. (AREJ) 23(1): 51-61.

Krishnappa G., Seetharamiah K., 1963, A new method of predicting the flow in a $90^{\circ}$ branch channel, Houille Blanche 7: 775-778.

Lama S.K., Kuroki M., Hasegawa K., 2002, Study of flow bifurcation at the $30^{\circ}$ open channel junction when the width ratio of branch channel to main channel is large, Ann. J. Hydraul. Eng. (JSCE) 46: 583-588.

Masjedi A., Taeedi A., 2011, Experimental investigations of effect intake angle on discharge in lateral intakes in 180 degree bend, World Appl. Sci. J. 15(10): 1442-1444.

Pirestani M.R., Vosoghifar H.R., Jazayeri P., 2011, Evaluation of optimum performance of lateral intakes, Int. J. Geol. Environ Eng. 5(8): 301-305.

Pirzadeh B., Shamloo H., 2007a, Investigation of characteristics of separation zones in T-junctions, Proc. of the 12th
WSEAS Int. Conf. on APPLIED MATHEMATICS, 29-31 December 2007, Cairo (Egypt): 189-193.

Pirzadeh B., Shamloo H., 2007b, Numerical investigation of velocity field in dividing open channel flow, Proc. of the 12th WSEAS Int. Conf. on APPLIED MATHEMATICS, 29-31 December 2007, Cairo (Egypt): 194-198.

Ramamurthy A., Satish M., 1988, Division of flow in short open channel branches, J. Hydraul. Eng. 114(4): 428-438.

Ramamurthy A., Tran D.M., Carballada L., 1990, Dividing flow in open channels, J. Hydraul. Eng. 116(3): 449-455.

Ramamurthy A., Qu J., Vo D., 2007, Numerical and experimental study of dividing open channel flows, J. Hydraul. Eng. 133(10): 1135-1144.

Taylor E.H., 1944, Flow characteristics at rectangular openchannel junctions, Trans. Am. Soc. Civil Eng. 109(1): 893-902.

Yonesi, H. A., Omid, M. H., and Haghiabi, A. H. (2008). A study of the effects of the longitudinal arrangement sediment behavior near intake structures, J. Hydraul. Res. 46(6): 814-819. 